Exclusion and Power: A Test of Four Theories of Power in Exchange Networks Author(s): John Skvoretz and David Willer

Source: American Sociological Review, Vol. 58, No. 6 (Dec., 1993), pp. 801-818

Published by: American Sociological Association

Stable URL: http://www.jstor.org/stable/2095952

Accessed: 10/12/2010 20:57

Your use of the JSTOR archive indicates your acceptance of JSTOR's Terms and Conditions of Use, available at http://www.jstor.org/page/info/about/policies/terms.jsp. JSTOR's Terms and Conditions of Use provides, in part, that unless you have obtained prior permission, you may not download an entire issue of a journal or multiple copies of articles, and you may use content in the JSTOR archive only for your personal, non-commercial use.

Please contact the publisher regarding any further use of this work. Publisher contact information may be obtained at http://www.jstor.org/action/showPublisher?publisherCode=asa.

Each copy of any part of a JSTOR transmission must contain the same copyright notice that appears on the screen or printed page of such transmission.

JSTOR is a not-for-profit service that helps scholars, researchers, and students discover, use, and build upon a wide range of content in a trusted digital archive. We use information technology and tools to increase productivity and facilitate new forms of scholarship. For more information about JSTOR, please contact support@jstor.org. 


\title{
EXCLUSION AND POWER: A TEST OF FOUR THEORIES OF POWER IN EXCHANGE NETWORKS*
}

\author{
JOHN SKVORETZ \\ University of South Carolina
}

\author{
DAVID WILLER \\ University of South Carolina
}

\begin{abstract}
We evaluate four theories that predict the distribution of power in exchange networks. All four theories-core theory, equidependence theory, exchange-resistance theory, and expected value theory-assume actors rationally pursue self-interests. Three of the theories add social psychological assumptions that place the pursuit of self interest in an interactive context. Predictions of exchange earnings by the four theories are evaluated against data from eight experimental networks, including types of networks not previously studied. These networks vary conditions that affect the chances that a position can be excluded from exchange. We find that when the theories base predictions on a network position's structural potential for exclusion, exchange-resistance theory provides the best fit, but when predictions are based on actual experiences of exclusion, expected value theory fits best. Our discussion focuses on the distinction between the a priori potential for exclusion versus experienced exclusion as factors in the genesis of power.
\end{abstract}

$\mathrm{T}$ he problem of power distribution in exchange networks has captured the attention of a variety of theorists. The appeal of the problem derives from the combination of the formal representation of social structure as network (Wellman and Berkowitz 1992) and sociology's perennial concern with power. A growing body of experimental studies now permits researchers to test various theoretical formulations. How does location in a network confer advantages on a person or a corporate body in their dealings with others? Consider the promotion prospects of two senior accountants, Andy and Bob. Because Andy's work involves accounts at various regional offices, his coworkers typically do not know each other. Bob, on the other hand, deals with corporate accounts, so his coworkers typically associate with each other. Thus, Andy and Bob are surrounded by two very different networks and it is not obvious that Andy's network favors him for promotion (Burt 1992). In a second ex-

${ }^{*}$ Direct all correspondence to: John Skvoretz, Sociology, University of South Carolina, Columbia, SC 29208. Research was supported by National Science Foundation Grant No. SES-9010888. Experiments were conducted at the University of South Carolina's Laboratory for Sociological Research with the assistance of Melissa Abboushi, Gina Finelli, Andy Hemmingsen, Sally Nickles, Jacek Szmatka, and Pidi Zhang. We appreciate the comments on earlier drafts by Michael Lovaglia and anonymous $A S R$ reviewers. ample, a university department searches for a chairperson who can negotiate with the college dean for support for the department. The common intuition that outsiders are more desirable is grounded in a belief that outsiders' network ties provide alternatives that insiders cannot match. These ties strengthen the outsider's hand, giving an outsider more power to negotiate favorable levels of support.

The strategic considerations quickly expand as alternatives distant in the network impact on the bargaining power of the dean and the leading candidate. Such considerations lead to the problem of power distribution as it has been addressed in the network exchange literature. This literature investigates the general properties of networks that influence the allocation of valued resources and focuses on how alternative positions remote in the network affect earnings from exchange in the network's ties.

We use experiments to evaluate four recent theories that predict power distribution/resource allocation in exchange networks. The four theories are game-theoretic core analysis (Bienenstock and Bonacich 1992), the equidependence principle (Cook and Yamagishi 1992), the expected value model (Friedkin 1992, forthcoming), and network exchangeresistance theory (Markovsky, Willer, and Patton 1988; Willer, Markovsky, and Patton 1989; Markovsky, Skvoretz, Willer, Lovaglia, and Erger 1993). 
The key question is which of the four theories best predicts observed power distributions. This evaluation of the theories' relative predictive powers contributes to a long-standing process of theory competition in this research field that is necessary to a field's development into a theoretic science (Wagner and Berger 1985; Lakatos 1970). We are also concerned with the theories' absolute predictive power: How well does the best fitting theory account for observed power distributions and how could its fit be improved? Our investigation uncovers new understandings about exclusion as a source of power in networks.

Our evaluation of the four theories is comprehensive-we examine resource distributions in eight different networks. These networks vary along three dimensions: (1) shape, as defined by the connections among positions; (2) number of exchanges available to each position; and (3) number of exchanges per connection. All previous studies have varied the first dimension; three studies have varied the second dimension (Brennan 1981; Markovsky et al. 1988; Skvoretz and Willer 1991); and none has varied the third. Varying the three dimensions allows us to extend the scope of each theory.

This extension of scope is valuable for two reasons. First, the applicability of theories to networks outside the laboratory is improved. Individuals are seldom limited to one exchange per partner, as most previous experiments have assumed. Furthermore, an experimental network that allows multiple exchanges per connection more closely resembles naturally occurring exchange structures. ${ }^{1}$ Investigation of these experimental networks shows how to modify the principles developed for simple structures to apply to the more complicated circumstances found in natural settings. Second, the extension of scope allows us to examine further the fundamental distinction between "strong power" and "weak power" networks

\footnotetext{
${ }^{1}$ Real networks-and the exercise of power in them-still differ in many ways from these experimental structures. In our view, extension of scope must continue in a stepwise fashion guided by a body of theoretical issues and concerns as formulated in ongoing research programs. In that context, permitting multiple exchanges per connection is a theoretically justified manipulation of a central initial condition of the research programs we evaluate.
}

that has recently emerged in the literature (Markovsky et al. 1993).

Power differences are measured by differential earnings per exchange. ${ }^{2}$ In strong power networks, earnings favor the advantaged position to an extreme degree: The advantaged position appropriates about 90 percent or more of the available resources, leaving 10 percent or less to the disadvantaged position. In weak power networks, earnings per exchange favor the advantaged position to a moderate degree: The advantaged position typically appropriates 60 to 75 percent of available resources. Why do networks differ so strikingly in the distribution of power?

Current thinking suggests that the critical factor is the potential for exclusion associated with a particular position in a network structure, i.e., the ways in which exchanges by some positions can preclude exchanges by other positions. For instance, if each position can exchange only once, the A-B-A network is a strong power network- $B$ is never excluded but one $\mathrm{A}$ is always left out. If each $\mathrm{A}$ offers increasingly better exchanges to $\mathrm{B}$ to avoid exclusion, extreme differences in resource distribution result. On the other hand, the four position A-B-B-A network is a weak power network-the Bs are never excluded, but exclusion of one or both of the As is not inevitable. Each B has only another B as an alternative to its $A$ and so each A needs only to better the other B's offer to avoid exclusion. In this network, moderate resource differentiation is expected.

The four theories agree, at least implicitly, that exclusion determines power. However, their predictions differ because each theory makes different assumptions about the effects of exclusion. Underlying these differences is the question of whether exchange outcomes are determined by the a priori potential for exclusion or the actual experience of being ex-

\footnotetext{
${ }^{2}$ We do not evaluate predictions about the relative frequency of exchanges between particular positions for three reasons. First, some of the theories do not make such predictions. Second, some predictions of frequency of exchange are imprecise, e.g., "few" exchanges are anticipated (Bienenstock and Bonacich 1993). Third, precise predictions often are a priori assumptions of structural potential that are not necessarily intended to predict observed frequencies of exchange (Markovsky 1992; also see Lovaglia and Skvoretz 1993).
} 
cluded. We address this question and thus carry the investigation of network exchange one step further than previous studies.

\section{FOUR THEORIES OF POWER IN EXCHANGE NETWORKS}

The concept of power has a precise meaning in the literature on exchange networks. Exchange usually is an agreement between two actors on the division of a pool of resources or "profit" points. ${ }^{3}$ Power is indicated by a division of resources that significantly favors one actor over another: The actor with the larger share is said to be exercising power over the actor with the smaller share (cf. Cook and Emerson 1978; Willer 1992). The interpretation that power is being exercised is consistent with the idea that actors rationally pursue self-interests and, therefore, would not voluntarily agree to a small share if a larger share were possible.

The four theories share one fundamental assumption: Power differentials between actors are related to differences in actors' positions in the network of exchange relations. That is, the determinants of power, as revealed through "exchange outcomes of power use" (Molm 1990), are actors' structural locations rather than their strategic actions. ${ }^{4}$ The key theoretical problem is identifying the structurally advantaged positions in a network, i.e., the positions that will exercise greater power in exchange relations.

Proposals range from simple measures (e.g., positions connected to many other positions are more advantaged than those connected to few

${ }^{3}$ This task is formally equivalent to exchange formulated as an Edgeworth box problem (Edgeworth 1881). In Edgeworth's formulation, both actors can improve on their "initial" endowment by exchanging until some point on the "contract curve" is reached. At that point, any further exchange necessitates a decline in one actor's utility and an increase in the other's. Similarly, in the present task, both actors gain from any agreement because failure to reach agreement results in no payoff to either actor. However, any agreement that gives a larger share to one person necessarily gives a smaller share to the other, as do exchanges along the contract curve of the Edgeworth box.

${ }^{4}$ Strategic action refers to how subjects use their potential power advantages. Although strategic action can affect the use of power, Molm (1990) showed that strategic action is unrelated to structural advantage. other positions) to more complicated graphtheoretic attributes like "vulnerability" (Cook and Emerson 1978; Cook, Gillmore, and Yamagishi 1986; Willer 1986). The measure with the widest empirical support is the Graph Power Index (GPI) of Markovsky et al. (1988). The four theories we examine go beyond the ordinal predictions of these efforts to the more difficult task of predicting exact earnings from exchanges between pairs of positions. All four theories assume actors are rational-they attempt to maximize their payoffs from exchanges. All but core theory make some additional social psychological assumptions about an actor's propensity to agree to particular terms of exchange. Core theory is a "strategic" theory because it emphasizes the purely strategic determinants of the terms of exchange. The other three theories are "social psychological" theories because, while they do not ignore strategic determinants, they augment them with social psychological considerations. (Details of each theory are presented in the Appendix.)

\section{Core Theory}

Core theory views exchanges in networks in terms of cooperative $\mathrm{N}$-person game theory. Because exchanges provide value to actors, a set exchange agreement assigns a payoff vector to the set of actors. Vectors that meet three "rationality" conditions constitute the "core" of the exchange network qua game. These conditions are individual, subgroup (coalition), and group rationality. Individual rationality demands that each actor's payoff be equal to or greater than the payoff he or she can earn as a one-member coalition (which is zero by definition in exchange networks). Coalition rationality requires that the sum of the payoffs to any subset of actors is equal to or greater than the sum of payoffs that the subset can obtain by exchange agreements only among its members. Group rationality is coalition rationality at the network or complete group level.

The core of an exchange network qua game may contain one, many, or no outcomes, that is, the network may be strategically determined, underdetermined, or undetermined. In general, the payoff schedule will favor some positions over others. ${ }^{5}$ In most cases, the ac-

\footnotetext{
${ }^{5}$ For example, if all positions exchange only once when dividing a 24-point pool, the simple $\mathrm{A}_{1}$ -
} 
tual payoffs to a particular position in the core outcomes can vary widely. In one core outcome, a position may get 100 percent of the resources while in another core outcome, that position may get 0 percent. As a theory of exchange outcomes, core analysis simply predicts that some core outcome will occur. Because no specific social psychological principle is assumed, rationality considerations alone cannot always single out a particular outcome from this set. This indeterminacy makes comparisons with approaches that make point predictions difficult. To compare core theory with the other three theories, we follow Skvoretz and Fararo (1992) and assume that each core outcome is equally likely. Predictions are the average payoffs to the various positions, calculated over the core outcomes. For exchange networks that have no core outcomes (i.e., are strategically undetermined networks), core theory makes no prediction, although Bienenstock and Bonacich (1992) suggested that exchanges will be concluded but the bargaining will be unstable, "groups ... should take longer to arrive at their agreements and the patterns should be more variable" (p. 238).

\section{Equidependence Theory}

In equidependence theory, ego evaluates potential exchanges with a particular alter with two considerations in mind: How much ego will get in an exchange with this alter, and how much ego could get in an exchange with some other partner. The possible payoff from an alternative partner is ego's comparison level for exchanges with a given alter. The difference between this level and alter's offer determines how dependent ego is on exchanges with alter for favorable outcomes. Meanwhile, alter is evaluating exchanges with ego in a similar fashion and thus evaluating his or her dependence on ego for favorable outcomes. When ego and alter are equally dependent on their relation for relatively favorable outcomes, the relation is said to be equidependent. Given ego's

$\mathrm{B}-\mathrm{A}_{2}$ structure has a single core outcome, namely, a payoff of 24 points to $B$ and 0 to each of the As. Any other payoff assignment, say, 23 to $B, 1$ to $A_{1}$ and 0 to $A_{2}$ violates coalition rationality for some subset, in this case, $B$ and $A_{2}$ because the sum of their payoffs is 23 which is less than they could obtain by exchanging with each other. and alter's comparison levels, equidependence depends on the payoffs the two earn from exchange with each other.

An example given by Cook and Yamagishi (1992) illustrates the idea. Suppose $i$ and $j$ are negotiating over a 24-point pool and $i$ has another partner who guarantees $i 10$ points, while $j$ has no other partner. If $i$ and $j$ divide the pool at 13 for $i$ and 11 for $j$, actor $i$ gets 3 points more than her next best alternative (10), while $j$ gets 11 points more than her comparison level of 0 . Thus, $j$ is more dependent on $i$ than $i$ is on $j$ and $j$ "will be more willing to give up resources in order to conclude a successful transaction" (Cook and Yamagishi 1992, p. 247). In this example, equidependence is achieved when $i$ gets 17 points and $j$ gets 7 points because then $i$ and $j$ make 7 points more than their next best alternatives.

In networks larger than the dyad, this interdependent evaluation process goes on simultaneously in each of the network's ties. ${ }^{6}$ Equidependence theory's basic claim is that exchange earnings are determined when all ties in the network have achieved equidependence by appropriate adjustment of the terms of exchange in each of the network's ties. At this point, actor $i$ 's structural power is defined as the maximum profit $i$ can get from any of his or her partners. Observed earnings from exchanges are expected to be proportional to structural power.

\section{Expected Value Theory}

Friedkin's (1986) expected value theory follows from his general conceptualization of network effects. A structure defines a space of potential networks, each of which can be realized on a particular occasion. Predictions about a structure's outcomes are then expected values-outcome values of a particular network weighted by the probability of its occurrence. In the present context, a particular exchange

\footnotetext{
${ }^{6}$ For example, in the simple $A_{1}-B-A_{2}$ network, equidependence theory predicts $B$ gets all 24 points in an exchange with an A. Each $\mathrm{A}$ has no alternative and so has a comparison level of 0 . Receiving 0 in an exchange with $B$ makes $A$ 's dependence on $B$ equal to 0 . For $B, A_{2}$ is an alternative to $A_{1}$ in which $B$ receives 24 points. This establishes the comparison level for the 24 points received from an exchange with $A_{1}$, making $B$ 's dependence on $A_{1}$ equal to $A_{1}$ 's dependence on $B$, namely, 0 .
} 
network constitutes a structure and a maximally complete exchange pattern, i.e., one in which no further exchanges are possible, constitutes one element in the space of potential networks. ${ }^{7}$

The basic property of interest for each pair of actors $i$ and $j$, is whether actor $i$ 's failure to exchange with actor $j$ implies that actor $i$ is excluded from any exchange. Taken over all maximally complete outcomes, this propertythe degree to which actor $i$ is excluded from any exchange because he or she fails to exchange with actor $j$-defines the dependency of $i$ on $j$. Dependency is the operative social psychological consideration for expected value theory. Ego's aspirations depend on ego's dependency on alter: If ego's dependency on alter is low, ego's aspirations are high, and if ego's dependency on alter is high, ego's aspirations are low. Calculating the dependencies of actors on one another requires an assumption about the likelihood of a particular maximally complete exchange pattern. Friedkin's baseline assumption is that all maximally complete patterns associated with a network are equally likely. ${ }^{8}$

Expected value theory assumes an offermaking function that translates a particular degree of dependency into an offer to alter. The predicted earnings from exchange are then a function of the reciprocal offers as modified by compromises when the offers are inconsistent. Unlike equidependence theory, there is no explicit assumption that these predicted terms of exchange equalize or balance out, in a psychological sense, the differential dependencies of actors on one another. Nevertheless, differential dependency focuses the aspirations of actors on a range of terms of exchange that are sensitive to their dependency on one another.

\footnotetext{
${ }^{7}$ In the line network A-B-B-A, there are two maximally complete exchange patterns, one in which two $A B$ exchanges occur and one in which the two $\mathrm{B}$ positions exchange. In the second exchange pattern, even though both A positions do not exchange, the pattern is maximally complete because the two A positions are not connected and thus no further exchanges can be made.

${ }^{8}$ In the $A_{1}-B-A_{2}$ network, the $A_{1}-B$ and the $A_{2}-$ $B$ exchange patterns are equally likely. $B$ 's dependency on either $A$ is 0 because $B$ is never excluded, while each A's dependency on B is .5 because A fails to exchange with $B$ and so is excluded 50 percent of the time.
}

\section{Exchange-Resistance Theory}

Network exchange-resistance theory assigns a Graph Power Index (GPI) score to each node in a network. GPI sums "nonintersecting" paths from a node by adding odd length paths, which are advantageous, and subtracting even length paths, which are disadvantageous..$^{9}$ Relative GPI scores and three axioms predict with whom a position's occupant will seek to exchange. Agreements are assumed to occur only if actors mutually seek to exchange. The original theory made only ordinal predictions of earnings: If two positions have equal GPI scores, an equal division of points is expected, whereas if $i$ has a higher GPI score than $j, i$ is expected to receive a larger share. Subsequent work (Markovsky et al. 1993) identified $\mathrm{GPI}_{i}>\mathrm{GPI}_{j}$ as leading to strong power differences-extreme differentiation in earnings - and extended the theory to predict "weak power" differences-moderate differences in earnings - in networks in which structurally dissimilar positions have the same GPI score. Weak power occurs when the pattern of exchange-seeking differentially affects a node's likelihood of being included in an exchange. This extension of the theory is also limited to ordinal predictions.

To make this approach comparable to the other three theories, we propose a parsimonious model that unites the strong power and weak power analyses. To produce point predictions, we blend the exchange-seeking assumptions of GPI analysis with an actor's resistance to a particular set of terms of exchange (Heckathorn 1980; Willer 1981). ${ }^{10}$ An actor's resistance to a set of terms declines as these terms become increasingly favorable (see Appendix). In our unified model, the exchange-

${ }^{9}$ Odd length indicates advantage because it means a node has alternatives or a partner's alternatives also have alternatives to one's partner and so on. Even length indicates disadvantage because it means a node has one or more rivals for the attention of a partner.

10 Recent work has used resistance concepts (Lovaglia, Skvoretz, Willer, and Markovsky 1993). However, that work is not comparable to the other three theories because it was developed to predict weak power "equilibrium" rates only. Resistance in our analysis provides a "baseline" model chosen more with an eye toward simplicity of calculation and comprehensiveness of coverage than precise fit to a subset of exchange networks. 
seeking activity implied by GPI analysis and its extension modify resistance such that a high probability of exclusion lowers resistance to a particular set of terms. GPI calculations are necessary to apply this model-the relative scores determine the pattern of exchange-seeking activity and the resulting likelihood of exclusion. However, resistance is the relevant social psychological consideration for actors that makes point predictions possible. Actors make, accept, or reject offers based on their resistance to the proposed terms of exchange and converge on a set of terms to which both parties are equally resistant. This point of "equiresistance" exists and is uniquely specified for all connected pairs in a network. ${ }^{11}$

\section{Summary}

The theories of equidependence, expected value, and exchange-resistance are social psychological theories because they assume actors are guided by more than simple rationality in their negotiations with a particular alter. Actors are assumed to be sensitive to their alternatives (or lack thereof) and thus to the possibility they can "exit" from a particular relationship. Equidependence theory emphasizes the payoff from exit (the comparison level); expected value theory highlights the opportunities to exit without incurring costs (the probabilistic concept of dependency); and exchange-resistance theory combines both considerations through a resistance function that is modified by an actor's probability of being excluded. These assumptions enable the theories to "solve" network structures that core theory, which is based solely on the assumption of rational actors, leaves strategically underdetermined or undetermined.

\section{METHODS AND EXPERIMENTAL NETWORKS}

Subjects are undergraduates at a large university who participated for pay. All subjects received general information on the nature of the experiments, in particular, that the aim was to study the effects of network structure on nego-

\footnotetext{
${ }^{11}$ In the $A_{1}-B-A_{2}$ network, the exchange-seeking activity as determined by positions' relative GPI scores implies that B's probability of being included is 1.00 while A's is .5. In the unified model,
}

tiation. They were told that each resource-pool consisted of 24 points, how each profit point would be translated into money, and how exchanges were to be made. Subjects negotiated through ExNet, a system of networked PCs, in a "full information" design. The experimental network was displayed at each subject station and the screen displayed and continually updated the status of all offers and completed exchanges. Before the experiment, subjects were shown how to read the screen and how to make, accept, or reject and confirm offers. A short training session tested their understanding of these directions, followed by a practice session in which subjects negotiated with simulated others. The practice rounds used a different network than the experimental network and the randomly generated actions of the simulated actors were purposely unrealistic to avoid cuing effects.

Each experimental run was divided into periods and rounds with periods. Each run of a particular network involved a different group of subjects. The run typically had as many periods as positions in the network. Each period was divided into four rounds. Each round had a five-minute time limit on negotiations. Subjects changed locations in the network between periods in a manner designed to permit the estimation of the effects of particular subject pairs. At the end of each round, subjects were told their earnings in that round. At the end of the experimental run, subjects were paid an amount based on the points they earned. Subjects earned an average of $\$ 10.00$.

The eight experimental networks are diagrammed in Figure 1 and identified by simplified labels. The number of circles around a position indicates the number of exchanges the position can make per round. The number of lines connecting positions indicates the number of exchanges per round that can occur between the pair. Six networks are "unique-exchange" regimes because, as indicated by the single lines between nodes, only one exchange per connection is allowed per round. In these networks, positions that can make $\mathrm{N}>1$ exchanges per round must make them with $\mathrm{N}$ others.

an 18/6 exchange favoring $B$ is one for which B's resistance is low at .25 but still greater than A's at 177. The point of equiresistance is a $19.6 / 4.4$ division, at which point the resistances of $\mathrm{A}$ and $\mathrm{B}$ are equal at .183. 

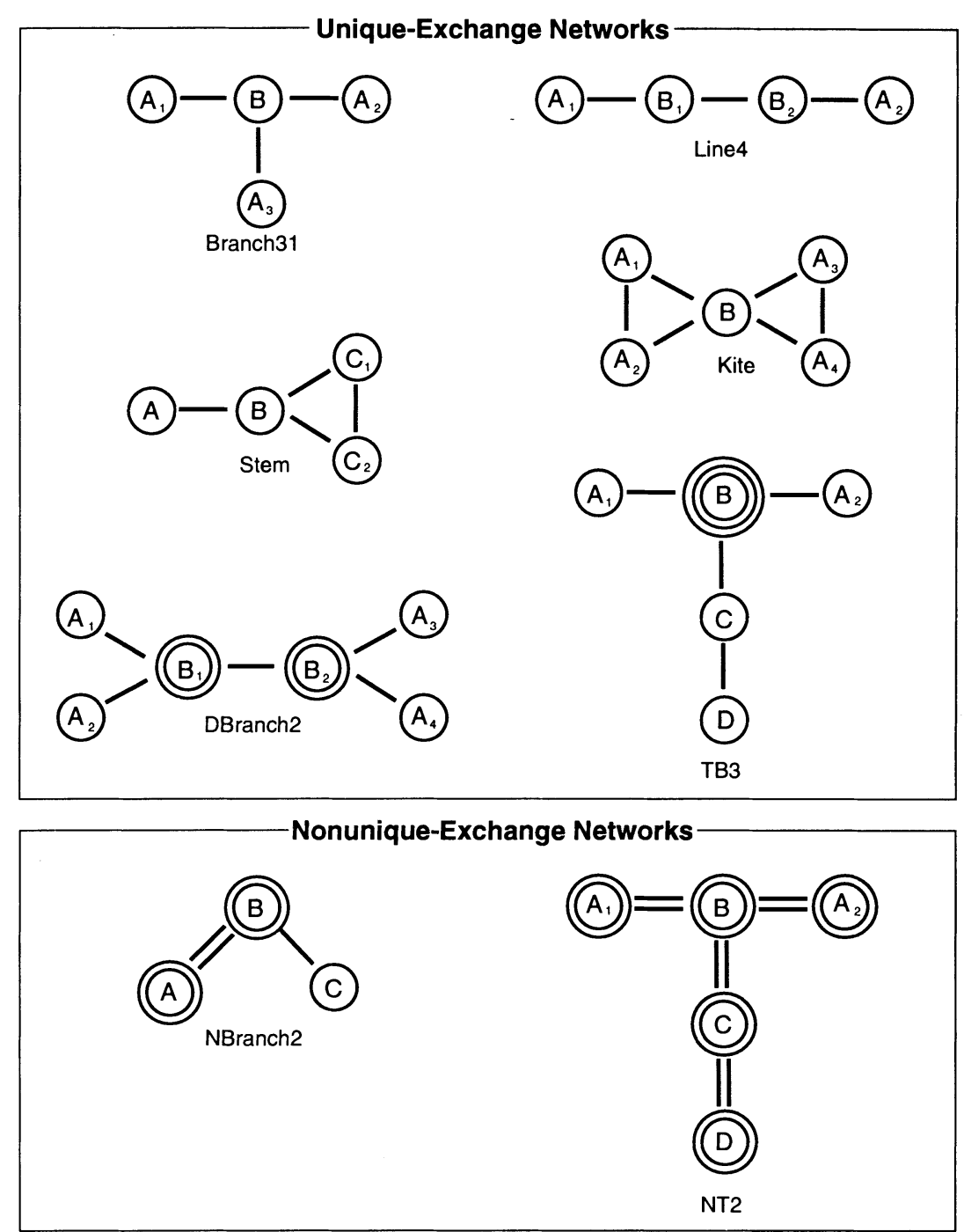

Figure 1. Experimental Networks Used in the Analysis

Two networks are nonunique-exchange regimes. In NBranch2, A and B can make two exchanges per round and $\mathrm{C}$ can make one, while A and B can exchange with each other twice per round. In NT2, all positions can make two exchanges per round and all pairs can exchange with each other twice per round. In these networks, negotiations for a pair's second exchange begin after the first exchange is completed; pairs cannot simultaneously negotiate the terms of the first and second exchanges. ${ }^{12}$

\footnotetext{
${ }^{12}$ Several considerations motivated the choice of networks. Four of the networks are of long-standing interest. The Branch 31 and Line 4 structures are
}

In all networks, actors connected to several others can negotiate simultaneously with each partner. The derivation of predictions from each of the four theories is straightforward for the unique-exchange networks, whereas each theory must be extended to cover the nonunique networks (details are presented in the Appendix).

To compare predictions with observations we estimated the effects of network position

among the simplest of the strong power and weak power networks, respectively; Stem and Kite are controversial weak power networks (Yamagishi and Cook 1990; Markovsky, Willer, and Patton 1990). 
from the observed points earned by exchange. Because particular agreements could involve the same pair of subjects, point earnings are analyzed as a variant of a repeated measures, correlated observations problem (Skvoretz and Willer 1991; Winer 1962). The units of observation are particular subject pairs that can complete a series of exchanges. A particular pair can contribute more than one exchange agreement to the total set of observations. A constrained regression technique is used to estimate the effects of network position and, where possible, the effects of particular subject pairings. The analytical procedure is a variant of a procedure used in previous research (Skvoretz and Willer 1991; Markovsky et al. 1993).

In the original procedure, $Y_{i}$ refers to the number of points earned by one member of the pair that completes the $i$ th agreement. The earnings of the same subject in a pair must be used to code all agreements made by that pair. We index subjects by numerals so that $Y_{i}$ refers to the earnings of the subject with the higher index number in the pair making the $i$ th agreement. For each pair that could complete an agreement, there is a $0 / 1$ variable denoted $V(x, y)$. For the $i$ th agreement, $V(x, y)=1$ if that agreement is between subjects $x$ and $y$ and otherwise, $V(x, y)=0$. For each structurally distinct exchange relation involving structurally distinct positions, there is an indicator variable $Z_{k}$. For the $i$ th agreement, $Z_{k}=1$ if the subject with the higher index value occupies the advantaged position; $Z_{k}=-1$ if he or she occupies the disadvantaged position; and $Z_{k}=0$ otherwise (i.e., when the $i$ th agreement is between persons not in the $k$ th structurally distinct exchange relation). The choice of which position is

The remaining four networks extend the scope of research in two ways: (1) they allow variation in the number of exchanges a position can make, and (2) they introduce networks that allow multiple exchanges per round between connected pairs. The Tshaped networks have played an important role in the history of network exchange research, motivating both theoretical and empirical work (see Cook, Emerson, Gillmore, and Yamagishi 1983; Willer 1986; Cook et al. 1986). The NBranch2 structure is the simplest nonunique network that has no uniqueexchange counterpart. Finally, the DBranch2 structure is the first multiple-exchange network to be researched that should exhibit the effects of weak power. Previous investigations of this effect (Markovsky et al. 1993) have been limited to the Kite and Stem unique networks. advantaged is arbitrary but must remain constant over the coding of agreements. (If a position initially coded as advantaged is in fact disadvantaged, then the effect of $Z_{k}$ will be negative.) Structurally distinct positions are denoted in Figure 1 by different letters, and thus structurally distinct exchange relations must involve different pairs of letters. The basic estimation equation is:

$$
Y=12+\sum \pi_{x y} V(x, y)+\sum \tau_{k} Z_{k}+\varepsilon,
$$

in which a linear relation is assumed between the various independent variables and the exchange earnings.

The parameter $\pi_{x y}$ represents the effect of the individual pair of subject $x$ with subject $y$; the parameter $\tau_{k}$ represents the effect of structural position in the $k$ th structurally distinct exchange relation. The intercept is constrained to the baseline earnings of 12 points. This allows subject pair effects and position effects to be interpreted as additions to or subtractions from the even split of 12/12. In certain cases (e.g., when few exchanges occur between particular positions), it may not be possible to disentangle the effects of network position from the subject pair effects. In such cases, simple means are reported.

We used a variation on this procedure that calculates, for each subject pair, the mean values of $Y$ for each combination of structural conditions indexed by the $Z_{k}$ variables. We then estimated a constrained regression equation weighting each data point by the number of agreements that entered into its calculation. This procedure gives the same estimates of the structural parameter $\tau_{k}$, but yields larger standard errors for these estimates. ${ }^{13}$ Larger standard errors are appropriate at this early stage of theoretical predictions of exact earnings from exchange where the danger lies more in premature rejection of valuable ideas than in the acceptance of an incorrect hypothesis.

\section{RESULTS}

Table 1 lists the number and types of exchanges observed in each experimental net-

\footnotetext{
${ }^{13}$ The standard errors increase because we are throwing out degrees of freedom identified with the multiple observations on a single pair in a particular combination of structural conditions.
} 
Table 1. Number and Types of Exchanges by Network Structure

\begin{tabular}{lcccl}
\hline Network & $\begin{array}{c}\text { Number of } \\
\text { Periods }\end{array}$ & $\begin{array}{c}\text { Number of } \\
\text { Groups }\end{array}$ & $\begin{array}{c}\text { Number of } \\
\text { Exchanges }\end{array}$ & Type of Exchange \\
\hline Branch31 & 4 & 5 & 80 & $80 \mathrm{AB}$ \\
Line4 & 4 & 5 & 134 & $120 \mathrm{AB}, 14 \mathrm{BB}$ \\
Stem & 4 & 4 & 116 & $53 \mathrm{AB}, 8 \mathrm{AC}, 55 \mathrm{CC}$ \\
Kite & 5 & 4 & 158 & $47 \mathrm{AB}, 111 \mathrm{AA}$ \\
DBranch2 & 6 & 5 & 423 & $410 \mathrm{AB}, 13 \mathrm{BB}$ \\
TB3 & 5 & 4 & 218 & $140 \mathrm{AB}, 34 \mathrm{BC}, 44 \mathrm{CD}$ \\
NBranch2 & 6 & 4 & 236 & $143 \mathrm{AB}, 93 \mathrm{BC}$ \\
NT2 & 5 & 4 & 307 & $155 \mathrm{AB}, 4 \mathrm{BC}, 148 \mathrm{CD}$ \\
\hline
\end{tabular}

work. Each group was composed of subjects who had prior experience negotiating with other subjects (rather than simulated actors) in other network structures. ${ }^{14}$

Table 2 compares predictions from the four theories with observations. The general pattern of experimental results is consistent with previous research. Power advantage is extreme in strong power relations, such as the A-B relation in the Branch31 network. Only a modest advantage is found in the weak power networks-Line4, Stem, Kite, and DBranch2. Changing B's permitted number of exchanges from one to three in TB3 changes the relative advantage of all positions in a way anticipated by Markovsky et al. (1988) for a seven-person network. The NT2 network behaves much as did the simple $\mathrm{T}$ network also studied by Markovsky et al. (1988). Finally, although the results for NBranch2 have no precedent in the literature, the general intuition that $\mathrm{B}$ has an advantage in both relations is confirmed.

The exchange-resistance model is the best fitting model-it has the smallest mean deviation from estimated advantage, 1.37 points, when deviations are weighted by the number of exchanges. Equidependence is the better of the two remaining social psychological theories with an average deviation of 2.66 points. Expected value theory has an average deviation over 3 points. The place of core theory depends on the value assigned to its "no rate" cells. If core theory is penalized by assigning

14 Time and budget constraints necessitated using subjects in more than one network. Overall, 97 different individuals were used in the 35 different experimental groups listed in Table 1. these cells a score of 0 , it has the second worst fit ( 2.88 points); but if these cells are assigned a score of 12 , it is second best at 2.40 points. If we consider the number of predictions that fall within two standard errors of the estimated advantage, core theory fits worst (regardless of how empty cells are handled) - only one of its 11 predictions falls in this range. Exchange-resistance theory has five of 14 predictions within this range, equidependence theory has four, and expected value theory has three. That core theory fits least well is not surprising -it makes fewer assumptions than the other three. That exchange-resistance theory fits best is also, perhaps, to be expected because it uses exit costs and opportunities to make its predictions, whereas the other two social psychological theories use only one of these factors.

Although exchange-resistance theory fits best of the four theories, nine of its 14 predictions are outside two standard errors of the estimated advantage. Because there is room for improvement, we propose some variants of the present models. These variants explore the idea that better fits can be obtained by taking into account the actual frequencies of exclusion experienced by actors.

\section{REFORMULATION OF THE THEORIES}

We drop core theory from further consideration and focus on the three theories that employ social psychological principles because they make explicit point predictions for all networks. The three theories emphasize the importance of exclusion and its consequences in the determination of earnings from exchange. However, there are two different paths by 
Table 2. Points Earned by Advantaged Positions by Network Relation: Predictions From Four Theories Versus Estimates From Experiments

\begin{tabular}{|c|c|c|c|c|c|c|c|}
\hline \multirow[b]{2}{*}{ Network } & \multirow[b]{2}{*}{$\begin{array}{l}\text { Network } \\
\text { Relation }^{\mathrm{c}}\end{array}$} & \multicolumn{4}{|c|}{ Theory (Predicted Points) } & \multirow[b]{2}{*}{$\begin{array}{l}\text { Number of } \\
\text { Exchanges }\end{array}$} & \multirow[b]{2}{*}{$\begin{array}{r}\text { Estimated } \\
\text { Points (SE) }\end{array}$} \\
\hline & & Core & $\begin{array}{c}\text { Equi- } \\
\text { dependence }\end{array}$ & $\begin{array}{l}\text { Exchange- } \\
\text { Resistance }\end{array}$ & $\begin{array}{l}\text { Expected } \\
\text { Value }\end{array}$ & & \\
\hline Branch31 & $\mathrm{B} / \mathrm{A}$ & 24.0 & 24.0 & $21.2^{*}$ & $22.0^{*}$ & 80 & $\begin{array}{c}21.63 \\
(.49)\end{array}$ \\
\hline Line 4 & $\mathrm{~B} / \mathrm{A}$ & 16.0 & 16.0 & 16.0 & 21.1 & 120 & $\begin{array}{c}14.05 \\
(.40)\end{array}$ \\
\hline \multirow[t]{2}{*}{ Stem } & $\mathrm{B} / \mathrm{A}$ & 20.1 & 18.0 & 18.3 & 22.0 & 53 & $\begin{array}{r}15.29 \\
(.82)\end{array}$ \\
\hline & $\mathrm{B} / \mathrm{C}$ & $-^{\mathrm{a}}$ & $14.4^{*}$ & $15.2^{*}$ & $19.5^{*}$ & 8 & $\begin{array}{l}16.49 \\
(2.64)\end{array}$ \\
\hline Kite & $\mathrm{B} / \mathrm{A}$ & $-^{\mathrm{a}}$ & 12.0 & 12.5 & 12.0 & 47 & $\begin{array}{c}14.05 \\
(.77)\end{array}$ \\
\hline DBranch2 & $\mathrm{B} / \mathrm{A}$ & 16.8 & $16.0^{*}$ & 14.6 & 20.2 & 410 & $\begin{array}{r}15.50 \\
(.41)\end{array}$ \\
\hline \multirow[t]{3}{*}{ TB3 } & $\mathrm{B} / \mathrm{A}$ & 12.0 & 12.0 & 12.0 & 12.0 & 140 & $\begin{array}{c}13.53 \\
(.45)\end{array}$ \\
\hline & $\mathrm{C} / \mathrm{B}$ & 24.0 & 24.0 & 21.8 & 21.1 & 34 & $\begin{array}{l}17.88 \\
(1.01)^{\mathrm{b}}\end{array}$ \\
\hline & C/D & 24.0 & 24.0 & $16.0^{*}$ & 21.1 & 44 & $\begin{array}{c}17.72 \\
(.93)\end{array}$ \\
\hline \multirow[t]{2}{*}{ NBranch2 } & $\mathrm{B} / \mathrm{A}$ & 18.0 & 24.0 & 17.9 & 18.3 & 143 & $\begin{array}{c}16.12 \\
(.53)\end{array}$ \\
\hline & $\mathrm{B} / \mathrm{C}$ & 24.0 & 24.0 & 16.0 & 21.1 & 93 & $\begin{array}{c}17.76 \\
(.67)\end{array}$ \\
\hline \multirow[t]{3}{*}{ NT2 } & $\mathrm{B} / \mathrm{A}$ & 24.0 & 24.0 & 19.6 & 21.8 & 155 & $\begin{array}{r}20.67 \\
(.49)\end{array}$ \\
\hline & $\mathrm{B} / \mathrm{C}$ & $-^{\mathrm{a}}$ & $16.0^{*}$ & $12.0^{*}$ & $12.0^{*}$ & 4 & $\begin{array}{l}16.50 \\
(2.40)^{\mathrm{b}}\end{array}$ \\
\hline & C/D & $12.0^{*}$ & $12.0^{*}$ & $12.0^{*}$ & 17.4 & 148 & $\begin{array}{c}12.86 \\
(.70)\end{array}$ \\
\hline \multicolumn{2}{|c|}{$\begin{array}{l}\text { Weighted average absolute } \\
\text { deviation from estimate }^{d}\end{array}$} & $\begin{array}{c}2.40 \\
(2.88)\end{array}$ & 2.66 & 1.37 & 3.54 & & \\
\hline
\end{tabular}

* The null hypothesis that the estimated points equal the predicted points cannot be rejected at the .05 level.

a No prediction because the network has no core outcome (e.g., Kite) or no exchange is possible between the two positions. To compute the deviation, a value of 12 or $(0)$ is assigned to these cells.

b Simple estimate from mean values; all other estimates control for the effects of particular subject pairs.

${ }^{c}$ First position is the advantaged position.

${ }^{d}$ Weights are the number of exchanges.

which network structure can affect exchange earnings differentials through exclusion.

In one path, earnings differentials are produced by the built-in potential for exclusion, which varies among network positions. For example, in the Line4 network, the Bs, confident of never being excluded, bargain harder than the As who recognize the risk of demanding too much. Thus, As make concessions, Bs make demands, and terms of exchange come to favor the Bs even if no exclusion occurs. Because differential power is a consequence of possibilities of the network structure, it is independent of actual exclusion. Therefore, a priori probabilities of exclusion are the best predictors of positions' earnings from exchanges. This model is most compatible with an actor who rationally infers consequences, a 
“forward-looking actor" in Macy's (1990) terms.

In a second path, earnings differentials result because actors who are excluded adjust their offers upward while actors who are consistently included adjust their offers downward. Here concessions and demands are both direct consequences of actual events. In the Line 4 network, Bs are never excluded and thus they never make concessions, but the As are excluded, and when they are excluded they make better offers to the Bs. As a result, the terms of exchange between an A and a B will favor the $B$ position. Because differential power is a consequence of actually being excluded or included, its best predictors are the observed frequencies. This model is most compatible with an actor who rationally adjusts to past experience, a "backward-looking" actor in Macy's (1990) terms.

The previous section examined the networkspecific "exclusion potential" version of the three social psychological theories. The exchange-resistance and expected value theories clearly base their predictions on assumptions about a priori probabilities. Exchange-resistance theory uses the probabilities of being included to modify the resistance function; expected value theory uses the exclusion probabilities to calculate dependency scores. In equidependence theory, the relevant a priori assumption is the setting of an actor's comparison level, i.e., actors face an a priori dichotomous probability of being excluded of 0 (if they have alternatives) or 1 (if they have no alternatives).

We now consider the "actual exclusion" version of these theories to predict power differentials produced by different network structures. If the potential for exclusion causes power, the theories will predict best when using a priori probabilities. If actual exclusion causes power, the theories will predict best when using observed frequencies of exclusion. If both factors cause power, then each theory's predictions may or may not be improved depending on which mechanism is implicit in the theory. Using observed frequencies of exclusion will give different predictions if they (or related quantities) differ from their corresponding a priori values. Table 3 presents, for exchange-resistance theory, observed and a priori probabilities of being included; Table 4 presents, for expected value theory, observed and a priori de-
Table 3. Potential and Observed Probabilities of Being Included by Position in the Network: Exchange-Resistance Theory

\begin{tabular}{|c|c|c|c|}
\hline \multirow[b]{2}{*}{ Network } & \multirow{2}{*}{$\begin{array}{l}\text { Position in } \\
\text { Network }\end{array}$} & \multicolumn{2}{|c|}{ Probability of Being Included } \\
\hline & & Potential & Observed \\
\hline \multirow[t]{2}{*}{ Branch31 } & A & .333 & .333 \\
\hline & B & 1.000 & 1.000 \\
\hline \multirow[t]{2}{*}{ Line4 } & A & .750 & .750 \\
\hline & B & 1.000 & .925 \\
\hline \multirow[t]{3}{*}{ Stem } & A & .600 & .828 \\
\hline & B & 1.000 & .923 \\
\hline & $\mathrm{C}$ & .800 & .922 \\
\hline \multirow[t]{2}{*}{ Kite } & A & .795 & 841 \\
\hline & B & .821 & .588 \\
\hline \multirow[t]{2}{*}{ DBranch2 } & A & .833 & .872 \\
\hline & B & 1.000 & .908 \\
\hline \multirow[t]{5}{*}{ TB3 } & A & 1.000 & .875 \\
\hline & $\mathrm{B}($ in $\mathrm{A} / \mathrm{B})$ & 1.000 & .875 \\
\hline & $\mathrm{B}$ (in $\mathrm{B} / \mathrm{C})$ & .250 & .400 \\
\hline & $\mathrm{C}$ & 1.000 & .975 \\
\hline & $\mathrm{D}$ & .750 & .575 \\
\hline \multirow[t]{3}{*}{ NBranch2 } & A & .625 & .578 \\
\hline & B & 1.000 & .938 \\
\hline & $\mathrm{C}$ & .750 & .719 \\
\hline \multirow[t]{4}{*}{ NT2 } & A & .500 & .484 \\
\hline & B & 1.000 & .994 \\
\hline & $\mathrm{C}$ & 1.000 & .950 \\
\hline & $\mathrm{D}$ & 1.000 & .925 \\
\hline
\end{tabular}

pendency scores. For both tables, observed values can differ substantially from a priori calculations. Clearly, for positions that have alternatives, the probability of exchange with one of these alternatives is almost never 1 -the a priori assumption of equidependence theory.

Predictions from the structural potential for exclusion version of exchange-resistance and expected value theories are easily modified to take observed frequencies into account. Because both have terms that refer to relative frequencies of various events related to observed exclusions, we simply substitute the observed values for the a priori values. ${ }^{15}$ Predictions from equidependence theory are modified by weighting what ego would receive from any alternative by the observed relative frequency

${ }^{15}$ Friedkin (forthcoming) recommends exactly this procedure for applications of expected value theory when the information on relative frequencies is available. 
Table 4. Potential and Observed Dependency Scores by Network Relation: Expected Value Theory

\begin{tabular}{|c|c|c|c|}
\hline \multirow[b]{2}{*}{ Network } & \multirow[b]{2}{*}{ Relation } & \multicolumn{2}{|c|}{ Dependency Score } \\
\hline & & Potential & Observed \\
\hline \multirow[t]{2}{*}{ Branch31 } & $\mathrm{AB}$ & .667 & .667 \\
\hline & BA & .000 & .000 \\
\hline \multirow[t]{2}{*}{ Line 4} & $\mathrm{AB}$ & .500 & .250 \\
\hline & BA & .000 & .075 \\
\hline \multirow[t]{4}{*}{ Stem } & $\mathrm{AB}$ & .667 & .172 \\
\hline & BA & .000 & .047 \\
\hline & $\mathrm{BC}$ & .333 & .078 \\
\hline & $\mathrm{CB}$ & .000 & .047 \\
\hline \multirow[t]{2}{*}{ Kite } & $\mathrm{AB}$ & .200 & .159 \\
\hline & BA & .200 & .412 \\
\hline \multirow[t]{2}{*}{ DBranch2 } & $\mathrm{AB}$ & .400 & .146 \\
\hline & BA & .000 & .092 \\
\hline \multirow[t]{6}{*}{ TB3 } & $\mathrm{AB}$ & .000 & .125 \\
\hline & $\mathrm{BA}$ & .000 & .083 \\
\hline & $\mathrm{BC}$ & .500 & .200 \\
\hline & CB & .000 & .025 \\
\hline & $\mathrm{CD}$ & .000 & .025 \\
\hline & DC & .500 & .425 \\
\hline \multirow[t]{4}{*}{ NBranch2 } & $\mathrm{AB}$ & .250 & .422 \\
\hline & BA & .000 & .063 \\
\hline & $\mathrm{BC}$ & .000 & .005 \\
\hline & $\mathrm{CB}$ & .500 & .281 \\
\hline \multirow[t]{6}{*}{ NT2 } & $\mathrm{AB}$ & .600 & .513 \\
\hline & BA & .000 & .006 \\
\hline & $\mathrm{BC}$ & $.000^{\circ}$ & .006 \\
\hline & $\mathrm{CB}$. & .000 & .050 \\
\hline & $\mathrm{CD}$ & .000 & .050 \\
\hline & DC & .200 & .075 \\
\hline
\end{tabular}

that the particular alter exchanges with ego. ${ }^{16}$ Table 5 presents these modified predictions.

The effect of using actual frequencies of exclusion varies substantially among theories. For exchange-resistance theory, the average deviation increases from 1.37 to 1.88 points,

\footnotetext{
16 This modification follows an unpublished analysis proposed by Yamagishi (1993) that provides an algorithm for calculating equidependence predictions. The algorithm introduces a priori probabilities into the determination of an actor's comparison level and abandons the assumption that an ego and ego's next best alternative are sure to exchange. Our analysis uses observed frequencies in a way generally consistent with Yamagishi's algorithm.
}

but two more predictions (for a total of seven) are within two standard errors of the estimated advantage. For equidependence theory, improvement is made on both counts-five rather than four of the 14 predictions are within two standard errors of the estimated advantage and the average deviation decreases from 2.66 to 2.38 points. The expected value model shows striking improvement: The average deviation decreases dramatically from 3.54 to 1.36 points and nine of its 14 predictions fall within two standard errors of the estimated advantage. These results suggest that: (1) exchange-resistance theory emphasizes the structural potential for exclusion as a cause of power; (2) expected value theory emphasizes experienced exclusion; and (3) equidependence theory uses both the structural potential for exclusion and experienced exclusion. The general conclusion is that both forms of exclusion can produce power differentials.

This conclusion is supported by the data in Table 5, which show that all three theories have difficulty accounting for earnings advantages in the weak power networks (Line4, Kite, DBranch2 and, to a lesser degree, Stem). In these networks, no position is systematically excluded from exchange. ${ }^{17}$ As expected, the estimated advantages are relatively modest, but even so the "experienced exclusion" models consistently predict less advantage than is observed-13 out of 15 predictions. Further, for the Kite network, all three "experienced exclusion" models predict, contrary to observation, that the $\mathrm{B}$ position is at a disadvantage in exchanges with the As. This pattern of underprediction and misprediction suggests that advantage in weak power networks is sensitive to differences in positions' potentials for being excluded and that experienced exclusion is not necessary to produce such advantage.

\section{CONCLUSION}

We evaluated four recent theories of power distribution in exchange networks, one purely strategic theory and three social psychological theories. We examined eight different networks

\footnotetext{
${ }^{17}$ These networks contrast sharply with a strong power network like Branch31 in which two of the three A positions are systematically excluded on each round.
} 
Table 5. Points Earned by Advantaged Positions by Network Relation: Predictions From Three Modifed Theories Versus Estimates From Experiments

\begin{tabular}{|c|c|c|c|c|c|c|}
\hline \multirow[b]{2}{*}{ Network } & \multirow[b]{2}{*}{$\begin{array}{l}\text { Network } \\
\text { Relation }\end{array}$} & \multicolumn{3}{|c|}{ Theory (Predicted Points) } & \multirow[b]{2}{*}{$\begin{array}{l}\text { Number of } \\
\text { Exchanges }\end{array}$} & \multirow[b]{2}{*}{$\begin{array}{r}\text { Estimated } \\
\text { Points (SE) }\end{array}$} \\
\hline & & $\begin{array}{c}\text { Equi- } \\
\text { dependence }\end{array}$ & $\begin{array}{l}\text { Exchange- } \\
\text { Resistance }\end{array}$ & $\begin{array}{l}\text { Expected } \\
\text { Value }\end{array}$ & & \\
\hline Branch31 & $\mathrm{B} / \mathrm{A}$ & 24.0 & $21.2^{*}$ & $22.0^{*}$ & 80 & $\begin{array}{c}21.63 \\
(.49)\end{array}$ \\
\hline Line4 & $\mathrm{B} / \mathrm{A}$ & 13.0 & 15.0 & 15.8 & 120 & $\begin{array}{c}14.05 \\
(.40)\end{array}$ \\
\hline \multirow[t]{2}{*}{ Stem } & $\mathrm{B} / \mathrm{A}$ & 12.5 & $14.1^{*}$ & $15.2^{*}$ & 53 & $\begin{array}{c}15.29 \\
(.82)\end{array}$ \\
\hline & $\mathrm{B} / \mathrm{C}$ & $12.6^{*}$ & $12.5^{*}$ & $12.9^{*}$ & 8 & $\begin{array}{l}16.49 \\
(2.64)\end{array}$ \\
\hline Kite & $\mathrm{B} / \mathrm{A}$ & 8.1 & 7.2 & 10.1 & 47 & $\begin{array}{c}14.05 \\
(.77)\end{array}$ \\
\hline DBranch2 & $\mathrm{B} / \mathrm{A}$ & 12.3 & 12.6 & 13.4 & 410 & $\begin{array}{c}15.50 \\
(.41)\end{array}$ \\
\hline \multirow[t]{3}{*}{ TB3 } & $\mathrm{B} / \mathrm{A}$ & 12.0 & 12.0 & $13.1^{*}$ & 140 & $\begin{array}{c}13.53 \\
(.45)\end{array}$ \\
\hline & $\mathrm{C} / \mathrm{B}$ & $18.9^{*}$ & 20.5 & $16.5^{*}$ & 34 & $\begin{array}{l}17.88 \\
(1.01)^{\mathrm{a}}\end{array}$ \\
\hline & $\mathrm{C} / \mathrm{D}$ & 13.8 & $18.4^{*}$ & 19.6 & 44 & $\begin{array}{c}17.72 \\
(.93)\end{array}$ \\
\hline \multirow[t]{2}{*}{ NBranch2 } & $\mathrm{B} / \mathrm{A}$ & 19.1 & 18.0 & 18.5 & 143 & $\begin{array}{c}16.12 \\
(.53)\end{array}$ \\
\hline & $\mathrm{B} / \mathrm{C}$ & 14.2 & 15.7 & $18.5^{*}$ & 93 & $\begin{array}{c}17.76 \\
(.67)\end{array}$ \\
\hline \multirow[t]{3}{*}{ NT2 } & $\mathrm{B} / \mathrm{A}$ & $19.8^{*}$ & $19.7^{*}$ & $21.0^{*}$ & 155 & $\begin{array}{c}20.67 \\
(.49)\end{array}$ \\
\hline & $\mathrm{B} / \mathrm{C}$ & $16.9^{*}$ & $12.7^{*}$ & $13.5^{*}$ & 4 & $\begin{array}{l}16.50 \\
(2.40)^{\mathrm{a}} .\end{array}$ \\
\hline & $\mathrm{C} / \mathrm{D}$ & $12.1^{*}$ & $12.4^{*}$ & $12.7^{*}$ & 148 & $\begin{array}{c}12.86 \\
(.70)\end{array}$ \\
\hline \multicolumn{2}{|c|}{$\begin{array}{l}\text { Weighted average absolute } \\
\text { deviation from estimate }\end{array}$} & 2.38 & 1.88 & 1.36 & & \\
\hline
\end{tabular}

${ }^{*}$ The null hypothesis that the estimated points equal the predicted points cannot be rejected at the .05 level.

${ }^{\text {a }}$ Simple estimate from mean values; all other estimates control for the effects of particular subject pairs.

${ }^{b}$ First position listed is advantaged position.

${ }^{c}$ Deviations are weighted by the number of exchanges.

and tested two different versions of the three social psychological theories, a "structural potential for exclusion" version and an "experienced exclusion" version. The best theory is exchange-resistance theory when predictions are based solely on structurally determined potentials for exclusion, i.e., on a priori calculations of differential probabilities of exclusion (and related quantities) faced by different positions in a network. When predictions use $o b$ served instances of exclusion (and related quan- tities), expected value theory is the best theory. Further, expected value theory is the only social psychological theory whose fit is substantially improved by taking into account the observed frequencies of exclusion. Our conclusion highlights (1) the role played by differential chances of exclusion in the genesis of power differentials; (2) the significance of weak power networks for further research on power distribution in exchange networks; and, (3) information availability as a catalytic agent in the pro- 
cess by which a network's structural potential for exclusion impacts on exchange outcomes.

Our study strongly suggests that power distribution in exchange networks is sensitive both to the potential for exclusion and to actual exclusion. Generally, actors who are less often excluded earn more from exchange and, hence, exercise power in negotiations with actors who are more often excluded. But the influence of differences in the structural potential for exclusion cannot be ruled out: In weak power networks, differences in the potential for exclusion augment the differentiation in power derived from actual exclusion. In one exceptional case-the Kite network-the structural potential for exclusion overrides the effect of differences in experienced exclusion. Even though the central actor B is excluded from exchange more than twice as often as the peripheral A actors (41 percent versus 16 percent), B nevertheless earns moderately more points in exchange with actors in the A positions (14.05 versus 9.95 points).

Of course, this interpretation assumes that the structural potential for exclusion favors B. In fact, only exchange-resistance theory suggests that A has a slightly greater potential for exclusion than $\mathrm{B}$ and so provides a basis for B's greater earnings. (However, its prediction based on this difference in structural potential underestimates B's advantage.) Fortunately, other general theoretical arguments can be applied to this anomaly. Burt's (1992) concept of "structural holes" adds theoretical grounding for the expectation that a structural potential can override actual events in their joint determination of exchange outcomes. In the Kite network, Burt would argue, B's advantage derives from the fact that there are four structural holes in B's primary network (of six possible holes) while each A's primary network has no structural holes. The total constraint on the B position is substantially less than that on the $\mathrm{A}$ position (.56 versus .78), and the constraint that a particular A places on the $\mathrm{B}$ position is much less than the $\mathrm{B}$ position places on that A position (.14 versus .39). Therefore, following Burt, A's demands on B would be more negotiable from B's perspective than B's demands on A would be from A's perspective. Therefore, B's greater earnings from exchanges with an A are no surprise.

In general, the four theories do less well in accounting for power differentials in weak power networks than in strong power networks. Before the discovery of weak power, only two power conditions were recognized: Either there were power differentials-now termed strong - and earnings from exchange dramatically favored high power actors, or power was equal and so were earnings. Predictions were evaluated simply by testing whether earnings differed from the baseline of equal division. Furthermore, in strong or equal power networks, potential exclusion and actual exclusion could not be disentangled. In strong power networks, low power actors were potentially excludable and necessarily were excluded. In equipower networks (e.g., an isolated dyad), neither actor could exclude the partner without cost and so no exclusion occurred. Because earnings of actors in advantaged positions in weak power networks fall between these extremes and are different in different networks, weak power networks place greater demands on theory and theories must now supply point predictions. More important, however, unlike other types of networks, weak power networks permit a decoupling of the structural potential for exclusion from actual frequencies of exclusion. These networks enable researchers to investigate the conditions under which one or the other or both of these mechanisms account for exchange rate differentials.

Finally, future research should use weak power networks to systematically explore the relationship between information and the development of power. None of the four theories qualifies its predictions by considering information conditions. Yet theorists have long suspected that information available to actors can influence power differentials. For example, actors need more complete information to act on structural potentials for exclusion than on actual exclusions. Although our results suggest that either mechanism can produce power, our experiments were conducted in an open information context in which actors knew how their positions were connected in the larger network. With this information, subjects could make a cognitive assessment of their chances of exclusion and calibrate their behavior accordingly. However, we have no evidence that they make such assessments or that the effect of a structural potential for exclusion requires such assessments. Perhaps other mechanisms underlie the effects of a structural potential for exclusion on power distribution in information-poor 
environments or in information-rich environments with unobservant subjects. Certainly, exploration of the role of information should be conducted using weak power networks as they alone allow the structural potential for exclusion to be decoupled from actual instances of exclusion and thus permit systematic examination of the catalytic effect of information.

JoHN SKVORETZ is Professor and Chair of the Department of Sociology at the University of South Carolina. His research interests include formal models of social networks, action structures, and small-group and organizational processes.

DaVID WILLER is Professor of Sociology, University of South Carolina. His work contributes to extending and formalizing Elementary Theory. The theory seeks to establish relations between structure and activity and test those relations experimentally. Recent publications test predictions for strong and weak poser structures. He is currently completing research applying the theory to processes of power centralization in early modern states.

\section{APPENDIX}

\section{Core Theory}

To identify the core in a network, each subset of positions is assigned a value based on the total number of exchanges possible in the subset and the size of the pool to be divided (typically 24 points). This mapping from a subset of positions to its value is called the characteristic function of the exchange network qua game. For instance, in the Branch31 network, any $\left\{\mathrm{A}_{i}, \mathrm{~B}, \mathrm{~A}_{j}\right\}$ triple has the same value as an $\left\{\mathrm{A}_{i}, \mathrm{~B}\right\}$ pair, namely 24 , because in both cases $\mathrm{B}$ can divide a 24-point pool with only one of the As. In the Line4 network, the complete set of actors $\{\mathrm{A}, \mathrm{B}, \mathrm{B}, \mathrm{A}\}$ has a value of 48 because two exchanges are possible within the set of four actors (two $\mathrm{AB}$ exchanges) and each exchange is worth 24 points. Once the characteristic function is defined, core payoff assignments are those assignments that meet the three rationality conditions. For instance, the Branch 31 outcome in which $B$ gets 22 points, $A_{1}$ gets 2 points and $A_{2}$ and $A_{3}$ get 0 points is not a core outcome because the sum of B's payoff and $A_{2}$ 's payoff is less than 24 , the value of the $\left\{A_{2}, B\right\}$ subset. In the Line4 network, the outcome in which the B's divide the pool evenly at $12 / 12$ and the A's receive 0 is not a core outcome because the total payoff to each $\{A, B\}$ subset coalition is less than its value of 24 .

Branch31's one core outcome occurs when B receives all 24 points and the As receive 0 points. This is the only payoff assignment that satisfies the three rationality conditions. B's strong advantage derives from its strategic location with respect to subset values-B must be included in any subset for the subset to have a positive value. This is not true for any A position. The B positions are advantaged in Line 4 in a more subtle way. Because the B positions are connected, any core outcome must have payoffs to the B positions that total 24 points or more. Because the A positions are not connected, their point total can be less than 24. B's advantage in Line4 derives from its strategic location with respect to coalition rationality - it has a nonzero alternative to its coalition with A. However, the advantage is not as extreme as in Branch31 because the group rationality condition ensures that the core outcomes give nonzero payoffs to the A positions.

The core outcomes for each of the unique-exchange networks are defined by a set of inequalities that payoff vectors for core outcomes must satisfy. Bienenstock and Bonacich (1992) specified the inequalities for the first four experimental networks. For DBranch2, the relevant inequalities are $\mathrm{B}_{1}+\mathrm{B}_{2} \geq 24 ; \mathrm{A}_{1}+\mathrm{B}_{1}+\mathrm{A}_{2} \geq 48 ; \mathrm{A}_{3}+\mathrm{B}_{2}+\mathrm{A}_{4} \geq 48$; $\mathrm{A}_{i}+\mathrm{B}_{1}+\mathrm{B}_{2} \geq 48$ for $i=1,2,3,4 ; \mathrm{A}_{1}+\mathrm{B}_{1}+\mathrm{B}_{2}+\mathrm{A}_{i}$ $\geq 72$ and $\mathrm{A}_{2}+\mathrm{B}_{1}+\mathrm{B}_{2}+\mathrm{A}_{i} \geq 72$ for $i=3,4$. There are 70,525 core outcomes that satisfy these inequalities-each A receives an average payoff of 7.2 and each $B$ receives 16.8 points in an exchange with $A$. The TB3 network has 625 core outcomes because each A's payoff can vary from 0 to 24 , determining B's payoff between 0 and 48 , while C's payoff is fixed at 24 and D's at 0.

In the nonunique-exchange networks, our extension of Bienenstock and Bonacich's work assumes that the sequential aspect of the exchange protocol can be ignored. This means that a pair that can negotiate two 24-point deals per round is treated as if it is negotiating only one deal worth 48 points. For the NBranch2 network, the inequalities that define the core are: $A+B \geq 48$ and $B+C \geq 24$. B's averagc earnings are 36 points, A's 12 points, and $C$ earns nothing. For the NT2 network, the 1,875 core outcomes are those in which $\mathrm{A}_{1}=\mathrm{A}_{2}=0, \mathrm{~B}=48$ and $C+D=48$, so $C$ and $D$ each average 12 points.

\section{Equidependence Theory}

Actor i's profit in an exchange with actor $\mathrm{j}$, denoted $R_{i j}$, is.i's agreed share of the resource pool. Actor i's dependence on actor $\mathrm{j}, D_{i j}$, is the difference between the profit $i$ gets in an $\mathrm{i}-\mathrm{j}$ exchange and the quantity $A_{i j}$ which is the profit $i$ gets from his or her $m$ th best alternative where $m$ is the number of exchanges $\mathrm{i}$ is allowed. If $\mathrm{i}$ has only one exchange, then $A_{i j}$ can be defined by the equation:

$$
A_{l y}=\max _{k \neq \jmath}\left\{R_{i k}\right\} \text {. }
$$

The equidependence principle states that exchange earnings are determined by the point at 
which the dependence of $i$ on $j$ equals the dependence of $\mathrm{j}$ on $\mathrm{i}$ throughout the network, i.e., where $D_{i j}=D_{j i}$ for all connected pairs i and $\mathrm{j}$. For the six unique-exchange networks, the equidependence point is easy to calculate using the basic algorithm described in Cook and Yamagishi (1992). The algorithm begins with each pool divided equally, calculates the $A_{i j}$ values, then adjusts the $R_{i j}$ values, then recalculates the $A_{i j}$ values and adjusts the $R_{i j}$ values and so on until they converge. For instance, for the Line4 network, the algorithm converges in 20 step to the solution $R_{\mathrm{A}_{1} \mathrm{~B}_{1}}=R_{\mathrm{A}_{2} \mathrm{~B}_{2}}=8$, $R_{\mathrm{B}_{1} \mathrm{~A}_{1}}=R_{\mathrm{B}_{2} \mathrm{~A}_{2}}=16$, and $R_{\mathrm{B}_{1} \mathrm{~B}_{2}}=R_{\mathrm{B}_{2} \mathrm{~B}_{1}}=8$ in which $\mathrm{A}$ has structural power 8 and $\mathrm{B}$ has structural power $16 .^{\mathrm{a}}$

In nonunique-exchange networks, unlike uniqueexchange networks, some alternative exchanges are exchanges with the same partner. The question is whether such alternatives should be used in determining the comparison level for a particular exchange with that partner. The answer must be "no," otherwise actors could bid against themselves. The problem only arises when an actor's connection to another could have more exchanges per round than the actor is allowed. In that case, the "extra" exchange capacity of the connection is irrelevant and does not provide genuine alternatives. The algorithm is easily modified to take this restriction into account. The simplest procedure confines connections to the smaller of the total exchanges the partners can make. Then each partner's $m$ th best alternative, necessarily, is exchange with some other partner.

In the NBranch2 network, A can make two exchanges so A's comparison level to either one of these exchanges is determined not by the next best alternative but by the second best alternative, which is 0 because $\mathrm{A}$ has no second best alternative. $\mathrm{C}$

a This solution for the Line4 network makes some technically problematic claims. First, the payoff predictions for some pairs of positions are inconsistent with the pool division interpretation. In Line4, according to the $R_{i j}$ values, $\mathrm{B}_{1}$ earns 8 points in exchange with $\mathrm{B}_{2}$ and so too does $\mathrm{B}_{2}$, despite the fact that the pool size is 24 points. To circumvent this problem, Cook and Yamagishi invoke the structural power concept and assume that exchange earnings are proportional to structural power: The Bs are power equals and are predicted to divide at $12 / 12$. But using those predicted earnings as the operative $R_{i j}$ values violates the equidependence principle: $A$ 's next best alternative to 8 from $\mathrm{B}$ is 0 , for a dependence score of 8 , while B's next best alternative to 16 from A is 12 from the other B for a dependence score of 4 . The algorithm is easily modified to avoid these inconsistencies. However, to remain faithful to the published record, we use the original unmodified algorithm. can make one exchange, so C's comparison level is the next best alternative, which is also 0 . B can make two exchanges but has three opportunities and so has a nonzero second best alternative to any one of the three. The equidependence point gives B 24 points in any of B's three exchanges-the dependence of $\mathrm{A}$ on $\mathrm{B}$ and $\mathrm{B}$ on $\mathrm{A}$ equal 0 , as do the dependence of $\mathrm{B}$ on $\mathrm{C}$ and $\mathrm{C}$ on $\mathrm{B}$. (To be consistent with the sequential structure of the exchange regime, this prediction requires that B's first exchange be with $A$. If it were with $C$, the result is an isolated dyad whose equidependence point is a $12 /$ 12 division.) The NT2 network is solved similarly $-B$ gets 24 points in an exchange with either $A$ and 16 points in either exchange with $C$, and $C$ gets 12 points in either exchange with $D$.

\section{Expected Value Theory}

In expected value theory, the dependency of actor $\mathrm{i}$ on actor $\mathrm{j}, d_{i j}$, is defined as the joint probability that $i$ is excluded from an exchange and $i$ does not exchange with $j .{ }^{b}$ The dependency of $i$ on $j$ affects the "offer" $i$ makes to $j$ in accord with the following equation (for a 24-point pool):

$$
f_{l y}=24-23^{1-d_{l}}
$$

Thus if $d_{i j}=0$, i offers 1 point to $\mathrm{j}$ and claims 23 points, whereas if $d_{i j}=1$, then $\mathrm{i}$ offers 23 points to $\mathrm{j}$ and claims only 1 point. Actor $j$ 's offer to $i$ is determined in a similar manner. Further assumptions resolve situations in which the claims do not sum exactly to the pool size. In particular, (1) if the sum exceeds the pool size, actors "split-the-difference" and agree on the average of their two offers (so i gets one-half of the sum of his or her claim and j's offer); (2) if both actors claim less than one-half the pool size, they agree on a 12/12 division; and, (3) if the sum is less than the pool size, but one actor claims more than one-half, they agree on a division in which that actor gets what he or she claims and the rest is allocated to the other actor. These assumptions produce a wide range of cases in which a 12/12 division is predicted: All cases in which $d_{i j}$ and $d_{j i} \geq .205$ and $d_{i j}=d_{j i}$.

For the nonunique-exchange networks, we generalize the dependency concept as follows: $d_{i j}$ is the joint probability that " $\mathrm{i}$ fails to complete an allowed exchange" and, on that occasion, "i fails to exchange with $\mathrm{j}$." The second clause recognizes the possibility that because multiple exchanges can be made with the same partner in a round, i may have

\footnotetext{
${ }^{b}$ If actor $i$ has only one exchange partner $j$, then the probability of the joint event is simply equal to the probability that $i$ is excluded from an exchange. However, this equality may not hold when $i$ has more than one exchange partner and i can make more than one exchange.
} 
exchanged with $j$ on another occasion. The idea is that $i$ 's dependency on $j$ reflects the fact that $i$ is excluded from completing some potential exchanges as a result of the failure to complete as many exchanges with $j$ as the connection allows. For all networks, we use the baseline assumption that all maximally complete outcomes are equally likely.

The NBranch2 network has two maximally complete outcomes: A exchanges twice with $\mathrm{B}$ and $\mathrm{C}$ has no exchange, or B exchanges once with each $A$ and $C$. If these outcomes are equally likely, then $d_{\mathrm{BA}}=d_{\mathrm{BC}}=0$ because $\mathrm{B}$ completes all allowed exchanges in both outcomes; $d_{\mathrm{AB}}=.25$ because $\mathrm{A}$ fails to complete one exchange given four opportunities to exchange with $\mathrm{B}$; and $d_{\mathrm{CB}}=.50$ because $\mathrm{C}$ fails to complete one exchange given two opportunities to exchange with $B$. The NT2 network has five maximally complete outcomes. Because B and $\mathrm{C}$ always complete their allotted totals, their dependency scores are 0 . The A positions complete only 40 percent of their potential exchanges and so have a dependency on B of .60 , while D completes 80 percent of its potential exchanges and so has a dependency on $\mathrm{C}$ of .20 .

\section{Exchange-Resistance Theory}

The baseline predictions of exchange-resistance theory use the concept of "resistance." In the work of Heckathorn (1980) and Willer (1981), an actor's resistance to an outcome is a function of the payoffs from that outcome, the "best hope" outcome and the "conflict" outcome. Technically, the conflict outcome is the outcome given by the failure to reach agreement. Any outcome that yields payoffs for both actors that are just as good or better than the conflict outcome is in the "contract zone." An actor's best hope is the outcome in the contract zone that yields maximum payoff. In the experimental task of dividing a pool of $M$ profit points, we assume (as do all other theories) that utility is a linear function of points (see Fararo and Skvoretz 1993). Therefore, the best hope of both $\mathrm{i}$ and $\mathrm{j}$ is $M$ points, the conflict payoff is 0 points, and the resistances of $\mathrm{i}$ and $\mathrm{j}$ to a division in which $\mathrm{i}$ receives $x_{i}$ points and $\mathrm{j}$ receives $M-x_{i}$ points are:

$$
R_{i}=\frac{M-x_{i}}{M-0} \text { and } R_{j}=\frac{M-\left(M-x_{i}\right)}{M-0} .
$$

Agreement is predicted to occur on the outcome to which $i$ and $j$ are equally resistant. This is the "equiresistance principle." In the absence of any further considerations, this outcome is an equal division of the pool.

To coordinate with previous research, we incorporate an additional consideration into the resistance equation and assume that the numerator is a function of the probability that an actor is included in an exchange. In particular, we assume a power function in which the difference between the maximum payoff and what the actor would receive from an offer is raised to the power determined by the probability of being included. Thus, the baseline model for exchange-resistance theory assumes that the resistances of $i$ and $j$ are given by:

$$
\begin{aligned}
& R_{i}=\frac{\left(M-x_{i}\right)^{p_{t}}}{M} \\
& \text { and } \\
& R_{j}=\frac{\left[M-\left(M-x_{i}\right)\right]^{p_{j}}}{M},
\end{aligned}
$$

where $p_{i}$ and $p_{j}$ are the probabilities of being included for $i$ and $j$. Equating the resistances and simplifying yields an equation that can be solved for $x$ and which provides the baseline predictions in Table 2:

$$
\frac{\ln \left(M-x_{i}\right)}{\ln \left(x_{i}\right)}=\frac{p_{j}}{p_{i}} .
$$

The probabilities of being included depend on the pattern of exchange-seeking. This pattern, in turn, is determined by the relative GPI scores following either Markovsky et al.'s (1988) Axiom 2 that " $i$ seeks exchange with $j$ if and only if i's power is greater than $\mathrm{j}$ 's or if $\mathrm{i}$ 's power relative to $\mathrm{j}$ equals or exceeds that in any of i's other relations" (p. 225) or the weak power random-seek extension in Markovsky et al. (1993). For example, according to this analysis, A's probability of being included in Stem, a weak power network, is .60 while B's probability is 1.00 . Therefore, the points that $B$ should earn in exchanges with $\mathrm{A}$ is that value of $x$ for which $\ln (24-x)=.6 x$, which is 18.3. Extending this method to the nonunique-exchange networks is a simple matter because an actor cannot simultaneously negotiate multiple deals with another actor even if he or she can make more than one exchange per round with that alter. The only new element is that concluding a deal with such an alter may not eliminate that alter from the space of potential partners.

\section{REFERENCES}

Bienenstock, Elisa J. and Phillip Bonacich. 1992. "The Core as a Solution to Exclusionary Networks." Social Networks 14: 231-44.

$\rightarrow$. 1993. "Game-Theoretic Models for Exchànge Networks: Experimental Results." Sociological Perspectives 36: 117-35.

Brennan, John S. 1981. "Some Experimental Structures." Pp. 188-204 in Networks, Exchange and Coercion: The Elementary Theory and Its Applications, edited by D. Willer and B. Anderson. New York: Elsevier.

Burt, Ronald S. 1992. Structural Holes: The Social Structure of Competition. Cambridge, MA: Harvard University Press. 
$\rightarrow$ Cook, Karen S. and Richard M. Emerson. 1978. "Power, Equity and Commitment in Exchange Networks." American Sociological Review 43: 721-39.

$\rightarrow$ Cook, Karen S., Richard M. Emerson, Mary R Gillmore, and Toshio Yamagishi. 1983. "The Distribution of Power in Exchange Networks: Theory and Experimental Results." American Journal of Sociology 89: 275-305.

$\rightarrow$ Cook, Karen S., Mary R. Gillmore, and Toshic $\rightarrow$ Yamagishi. 1986. "Point and Line Vulnerability as Bases for Predicting the Distribution of Power in Exchange Networks: Reply to Willer." American Journal of Sociology 92: 445-48.

$\rightarrow$ Cook, Karen S. and Toshio Yamagishi. 1992 $\rightarrow$ "Power in Exchange Networks: A Power-Dependence Formulation." Social Networks 14: 24566.

Edgeworth, Frederik Y. 1881. Mathematical Psychics. London, England: Kegan Paul.

Fararo, Thomas J. and John Skvoretz. 1993. "Methods and Problems of Theoretical Integration anc $\rightarrow$ the Principle of Adaptively Rational Action." Pp. 416-50 in Theoretical Research Programs: Studies in the Growth of Theory, edited by J. Berger and M. Zelditch, Jr. Stanford, CA: Stanford Uni versity Press.

Friedkin, Noah. 1986. "A Formal Theory of Social Power." Journal of Mathematical Sociology 12: 103-26.

-1992. "An Expected Value Model of Social Power: Predictions for Selected Exchange Networks." Social Networks 14: 213-30

- Forthcoming. "An Expected Value Model of Social Exchange Outcomes." In Advances in Group Processes, vol. 10, edited by E. J. Lawler, B. Markovsky, C. Ridgeway, and H. A. Walker. Greenwich, CT: JAI Press.

Heckathorn, Douglas. 1980. "A Unified Model for Bargaining and Conflict." Behavioral Science 23: 73-85.

Lakatos, Imre. 1970. "Falsification and the Methodology of Scientific Research Programs." Pp. 91-196 in Criticism and the Growth of Knowledge, edited by I. Lakatos and A. Musgrave. Cambridge, England: Cambridge University Press.

Lovaglia, Michael J. and John Skvoretz. 1993. "Predicting Frequency of Exchange in Networks: The Biased Seek Method." Paper presented at the 1993 Sunbelt Social Networks Conference, 13 Feb., Tampa, FL.

Lovaglia, Michael J., John Skvoretz, David Willer, and Barry Markovsky. 1993. "Negotiated Outcomes in Social Exchange Networks." Paper presented at the 1993 meeting of the American Socio logical Association, 17 Aug., Miami Beach, FL.

$\rightarrow$ Macy, Michael W. 1990. "Learning Theory and the Logic of Critical Mass." American Sociological
Review 55: 809-26.

Markovsky, Barry. 1992. "Network Exchange Outcomes: Limits of Predictability." Social Networks 14: 267-86.

Markovsky, Barry, John Skvoretz, David Willer, Michael Lovaglia, and Jeffrey Erger. 1993. "The Seeds of Weak Power: An Extension of Network Exchange Theory." American Sociological Review 58: 197-209.

Markovsky, Barry, David Willer, and Travis Patton. 1988. "Power Relations in Exchange Networks." American Sociological Review 53: 220-36.

$\longrightarrow \rightarrow$. 1990. "Theory, Evidence and Intuition." American Sociological Review 55: 300-305.

Molm, Linda D. 1990. "Structure, Action, and Outcomes: The Dynamics of Power in Social Exchange." American Sociological Review 63: 81037.

Skvoretz, John and Thomas J. Fararo. 1992. "Power and Network Exchange: An Essay Toward Theoretical Unification." Social Networks 14: 325-44.

Skvoretz, John and David Willer. 1991. "Power in Exchange Networks: Setting and Structural Variation." Social Psychology Quarterly 54: 224-38.

Wagner, David and Joseph Berger. 1985. "Do Sociological Theories Grow?" American Journal of Sociology 90: 697-728.

Wellman, Barry and Stephen D. Berkowitz, eds. 1992. Social Structures: A Network Approach. New York: Cambridge University Press.

Willer, David E. 1981. "Quantity and Network Structure.” Pp. 108-27 in Networks, Exchange and Coercion: The Elementary Theory and Its Applications, edited by D. Willer and B. Anderson. New York: Elsevier.

$\rightarrow-$. 1986. "Vulnerability and the Location of Power Positions." American Journal of Sociology 92: 441-48.

1992. "The Principle of Rational Choice and the Problem of a Satisfactory Theory." Pp. 49-78 in Rational Choice Theory: Advocacy and Critique, edited by J. S. Coleman and T. J. Fararo. Newbury Park, CA: Sage.

Willer, David E., Barry Markovsky, and Travis Patton. 1989. "Power Structures: Derivations and Applications of Elementary Theory." Pp. 313-53 in Sociological Theories in Progress: New Formulations, edited by J. Berger, M. Zelditch, Jr., and B. Anderson. Newbury Park, CA: Sage.

Winer, B. J. 1962. Statistical Principles in Experimental Design. New York: McGraw-Hill.

Yamagishi, Toshio. 1993. "PDP: Power/Dependence Predictions." Hokkaido University, Japan. Unpublished algorithm.

Yamagishi, Toshio and Karen S. Cook. 1990. "Power Relations in Exchange Networks: a Comment on "Network Exchange Theory." American Sociological Review 55: 297-300. 